\title{
MELHORAMENTO DO TRIGO. VI. HEREDITARIEDADE DA TOLERÂNCIA A TRÊS CONCENTRACÕES DE ALUMÍNIO EM SOLUÇÃO NUTRITIVA ${ }^{(1)}$
}

CARLOS EDUARDO DE OLIVEIRA CAMARGO (2), Seção de Arroz e Cereais de Inverno, Instituto Agronômico.

\section{RESUMO}

No estudo dos cultivares de trigo C-3, BH-1146, Siete Cerros e Brevor em soluções nutritivas contendo oito concentrações de aluminio $(0,1,2,3,4,5,6$ e $10 \mathrm{mg} /$ litro), BH-1146 e C-3 mostraram tolerância a todas as concentrações de Al empregadas, e Brevor e Siete Cerros apresentaram-se sensiveis à presença de $1 \mathrm{mg} / \mathrm{litro}$ de Al ${ }^{3}+$ nas soluções. A tolerância a dada concentração de aluminio foi medida pela capacidade de crescimento da raiz primária central da planta em solução nutritiva completa, após um tratamento de 48 horas em solução contendo determinada quantidade de alumínio. Os cultivares C-3 e Siete Cerros, considerados pais, e as populações $F_{1}$ e $F_{,}$, provenientes dos seus cruzamentos, foram testados em soluções nutritivas contendo 3,6 e $10 \mathrm{mg} /$ litro de alumínio. Os resultados obtidos mostraram que, para $3 \mathrm{mg} / 1$ itro de aluminio, o cultivar C-3 diferiu de Siete Cerros por um par de genes dominantes para tolerância. Houve uma quebra gradual da dominância do par de genes responsável pela reação de tolerância quando se empregou a concentração de $6 \mathrm{mg} /$ litro de $\mathrm{Al}^{3+}$. O cultivar Siete Cerros diferiu do $\mathrm{C}-3$ por um par de genes dominantes para sensibilidade, quando foram estudados em solução nutritiva contendo 10mg/litro de $\mathrm{Al}^{3+}$, ou o C-3 diferiu do Siete Cerros por

(1) Trabalho parcialmente desenvolvido na Universidade Estadual de Or gon (EUA). Recebido para publicação a 27 de novembro đe 1981.

(2) Com bolsa de suplementação do CNPq. 
um par de genes dominantes para tolerâlıcia, nessa concentração, considerando que os individuos heterozigotos das populaçóes $F_{1}$ e $F_{2}$ apresentaram reação de sensibilidade. Os individuos heterozigotos das populações $F_{1}$ e $F_{2}$ revelaram tolerância a $3 \mathrm{mg} /$ litro, a qual foi diminuida a $6 \mathrm{mg} / \mathrm{litro}$, e apresentaram suscetibilidade total a 10mg/litro, com base na hipótese de a tolerância ser devida a um par de genes dominantes. Altos valores da herdabilidade em sentido amplo $(0,725$ a 0,895$)$ indicaram que a seleção para tolerância ao alumínio seria eficiente na população proveniente do cruzamento entre um cultivar tolerante (C-3) e um sensível (Siete Cerros). Com grandes populaçōes $F_{2}$, seria interessante selecionar as plantas em altas concentraçōes $\mathrm{de}^{2} \mathrm{Al}^{3}+(10 \mathrm{mg} / \mathrm{litro})$ na solução, pois seriam eliminadas as sensiveis (homozigotas recessivas e heterozigotas) e selecionadas as tolerantes homozigotas. Por outro lado, seria de interesse utilizar baixas concentrações de alumínio (3mg/litro) na solução quando pequenas pcpulações $F_{2}$ forem disponiveis, eliminando somente as plantas sensíveis (homozigotas recessivas) e selecionando as tolerantes (homozigotas e heterozigotas).

\section{INTRODUÇÃO}

A ocorrência de níveis tóxicos de alumínio, principalmente em solos ácidos, tem sido relatada por muitos pesquisadores como sendo bastante comum, principalmente na região do cerrado brasileiro.

Em virtude da existência de respostas diferenciais entre espécies e cultivares dentro de uma mesma espécie, em relação a altos níveis de alumínio, existe a possibilidade de desenvolver cultivares tolerantes para as regiões onde a prática da calagem ou o controle da acidez do subsolo sejam dificeis de executar (6).

Os cereais diferem largamente em suas respostas à presença de alumínio no solo, sendo a cevada mais sensivel do que o trigo, que é mais sensivel do que o centeio, aveia e arroz (5).

Os cultivares de trigo Siete Cerros e Tobari-66 foram sensiveis a 1 e $3 \mathrm{mg} /$ litro de alumínio na solução nutritiva respectivamente, enquanto Alondra-S-46, Alondra-S-45 e IAC-17 o foram a $6 \mathrm{mg} /$ litro. Os cultivares BH-1146, IAC-5, IAC-18, IAC-13 e Londrina foram tolerantes a $10 \mathrm{mg} /$ litro de alumínio na solução nutritiva, sendo BH-1146, IAC-18 e IAC-13 mais tolerantes que os restantes (4). Em vasos contendo solo com alumínio, o BH-1146 diferiu, em produção de grãos por planta, do Tobari-66, Alondra-S-46, LAC-17 e Siete Cerrros (4).

KERRIDGE \& KRONSTAD $(\boldsymbol{\gamma})$ verificaram que a diferença na resposta a $1,6 \mathrm{mg} /$ litro de alumínio na solução nutritiva entre os cultivares Druchamp e Brevor era devida a um único par de genes, com a tolerância ao alumínio sendo dominante. O conhecimento de que Druchamp não era tão tolerante quanto Atlas-66 sugeria que mais de um par de genes poderia estar envolvido na tolerância ao alumínio. 
Resultados com populações em geração $F_{1}, F_{2}$ e retrocruzamentos envolvendo cultivares de trigo tolerantes e sensiveis testados em solução nutritiva contendo $8 \mathrm{mg}$ /litro de alumínio, permitiram concluir que a suscetibilidade era devida a um par de genes recessivos e que a seleção para plantas sensiveis a essa concentração de alumínio na geração $F_{2}$ era efetiva. Seleção de plantas com reação intermediária de tolerância e tolerantes foi menos eficiente, indicando que a herança deste fator era mais complexa do que se julgava (8).

CAMARGO (2), estudando a herança da tolerância ao aluminio em solução nutritiva, mostrou que para $2 \mathrm{mg}$ /litro de alumínio o cultivar de trigo Tordo diferiu de Siete Cerros por um par de geres dominantes para tolerância; para 3mg/litro, o $\mathrm{BH}-1146$ apresentou um par de genes e Atlas-66 dois pares de genes dominantes, quando foram cruzados com Siete Cerros e Tordo; para 6mg/litro de Al, os cultivares BH-1146 e Atlas-66, quando foram cruzados entre si, mostraram ter um par de genes dominantes cada um; o mesmo cruzamento entre BH-1146 e Atlas-66, estudado a $10 \mathrm{mg}$ / litro, revelou que $\mathrm{BH}-1146$ diferiu do Atlas-66, que foi sensível a esta concentração, com um par de genes dominantes para tolerância.

Os objetivos deste estudo foram: 1) determinar a reação diferencial à toxicidade a oito concentrações de aluminio, em solução nutritiva, entre dois cultivares de trigo, sendo um sensivel e outro tolerante ao alumínio, em condições de solo; 2) obter informação sobre o tipo de ação genética envolvida na expressão da tolerância, considerando três concentrações de aluminio.

\section{MATERIAL E MÊTODOS}

O cultivar C-3, selecionado pela Secretaria da Agricultura do Estado do Rio Grande do Sul, e o Siete Cerros, introduzido do Centro Internacional de Melhoramento de Milho e Trigo (CIMMYT), México, foram submetidos a diferentes concentrações de aluminio em soluções nutritivas. O Brevor, selecionado na Universidade de Oregon, foi utilizado como controle sensivel e o BH-1146, selecionado no Instituto Agronômico de Belo Horizonte, como controle tolerante. A técnica usada para a avaliação da reação diferencial entre os cultivares foi a mesma citada por CAMARGO $(\mathbf{2 , 3 , 4 )}$ e transcrita a seguir: sementes dos quatro culiivares de trigo foram cuidadosamente lavadas com uma solução de hipoclorito de sódio a $10 \%$ e colocadas para germinar em caixas de Petri por 24 horas. Após esse tempo, as radículas estavam iniciando a emergência.

Foram escolhidas vinte sementes de cada cultivar e colocadas sobre o topo de oito telas de náilon postas em contacto com as soluções nutritivas de quatro vasilhas plásticas de 20 litros de capacidade cada uma, onde permaneceram crescendo por 48 horas. 
A composição final da solução nutritiva, referida como "solução base", foi a seguinte: $\mathrm{Ca}\left(\mathrm{NO}_{3}\right)_{2} 4 \mathrm{mM} ; \mathrm{MgSO}_{4} 2 \mathrm{mM} ; \mathrm{KNO}_{3} 4 \mathrm{mM}$; $\left(\mathrm{NH}_{4}\right)_{2} \mathrm{SO}_{4} \quad 0,435 \mathrm{mM} ; \mathrm{KH}_{2} \mathrm{PO}_{4} \quad 0,5 \mathrm{mM} ; \mathrm{MnSO}_{4} 2 \mu \mathrm{M} ; \mathrm{CuSO}_{4} \quad 0,3 \mu \mathrm{M}$; $\mathrm{ZnSO}_{4} \quad 0,8 \mu \mathrm{M} ; \quad \mathrm{NaCl} \quad 30 \mu \mathrm{M} ; \quad \mathrm{Fe}-\mathrm{CYDTA} \quad 10 \mu \mathrm{M} ; \quad \mathrm{Na}_{2} \mathrm{MoO}_{4} \quad 0,10 \mu \mathrm{M}$ e $\mathrm{H}_{3} \mathrm{BO}_{3} 10 \mu \mathrm{M}$. O nível da solução nas vasilhas plásticas foi tal de modo a tocar a parte de baixo da tela de náilon, de maneira que as sementes foram mantidas úmidas, tendo as radículas emergentes um pronto suprimento de nutrientes. $\mathrm{O} \mathrm{pH}$ da solução foi previamente ajustado para $4,0 \mathrm{com}$ uma solução de $\mathrm{H}_{2} \mathrm{SO}_{4} 1 \mathrm{~N}$. A solução foi continuamente arejáda e, as vasilhas plásticas contendo as soluções, colocadas em banho-maria a $25 \pm 1^{\circ} \mathrm{C}$ dentro de uma casa de vegetação da Universidade Estadual de Oregon (EUA), onde o experimento foi mantido com luz artificial contínua em sua totalidade. Decorridas as 48 horas iniciais, cada plântula tinha três raízes primárias: uma mais longa, medindo cerca de $4,5 \mathrm{~cm}$, e duas mais curtas, localizadas lateralmente à primeira. As oito telas de náilon contendo as vinte plântulas de cada uma dos quatro cultivares foram transferidas para as respectivas soluções tratamentos.

A composição das soluções tratamentos foi um décimo da solução base, exceto que o fósforo foi omitido e o ferro adicionado como $\mathrm{FeCl}_{3}$ em substituição ao Fe-CYDTA, como descrito por MOORE et alii (9). O fósforo foi omitido para evitar a possível precipitação do alumínio como $\mathrm{Al}(\mathrm{OH})_{3}$. $\mathrm{O} \mathrm{pH}$ das soluçōes tratamentos foi ajustado para cerca de 4,2 com uma solução de $\mathrm{H}_{2} \mathrm{SO}_{4} 1 \mathrm{~N}$. Quantidades crescentes de alumínio na forma de $\mathrm{Al}_{2}\left(\mathrm{SO}_{4}\right)_{2}, 18 \mathrm{H}_{2} \mathrm{O}$ foram adicionadas de modo a obter oito soluções tratamentos com as concentrações de $0,1,2,3,4,5,6$ e $10 \mathrm{mg} / \mathrm{li}$ tro de $\mathrm{Al}^{3 *}$ respectivamente. $\mathrm{O}$ pH final da solução foi ajustado para 4,0 com uma solução de $\mathrm{H}_{2} \mathrm{SO}_{4} \mathrm{IN}$, evitando-se adicionar solução de $\mathrm{NaOH}$, que poderia causar a precipitação do alumínio no local de queda da gota.

As plântulas ficaram crescendo por 48 horas nas respectivas soluçóes tratamentos. Decorrido esse periodo, a raiz primária de cada plântula foi medida e transferida de volta para as vasilhas contendo a mesma solução nutritiva base onde as plantas cresceram nas primeiras 48 horas.

As plântulas permaneceram crescendo na solução base por mais 72 horas. $O$ crescimento da raiz nestas 72 horas na solução base depende da concentração da prévia solução tratamento. Com uma quantidade excessiva de alumínio, as raizes primárias não crescem mais e permanecem grossas, mostrando no ápice uma injúria típica com descoloração. A quantidade de crescimento da raiz, após o tratamento com Al foi determinada, medindo-se novamente o comprimento da raiz de cada plântula no final das 72 horas na solução base e subtraindo-se seu comprimento no final de crescimento na respectiva solução tratamento.

Durante todo o experimento, o pH das soluçōes foi mantido o mais próximo possivel de 4,0 com ajustamentos diários. 
O delineamento utilizado foi parcelas subdivididas com duas repetiçōes. Cada repetição foi formada por oito parcelas, representadas pelas concentrações de alumínio e, cada parcela, dividida em subparcelas representadas por vinte plântulas de cada um dos quatro cultivares em estudo.

Os cultivares C-3 e Siete Cerros, considerados pais, e seus cruzamentos em geração $F_{1}$ e $F_{2}$, foram testados quanto à tolerância a 3 , 6 e $10 \mathrm{mg} /$ litro de alumínio, empregando-se a mesma técnica descrita anteriormente.

As frequiências de plantas tolerantes e sensíveis observadas nas três concentraçōes de alumínio estudadas foram computadas com base nas reaçōes de tolerância (crescimento da raiz após 48 horas em solução contendo uma concentração conhecida de aluminio) e suscetibilidade (paralisação do crescimento da raiz nas mesmas condiçōes). O teste de quiquadrado foi utilizado para comparar as freqüèncias obtidas e esperadas pela hipótese de segregação de um par de genes.

Foram estimados os valores da herdabilidade em sentido amplo para a tolerância às três concentrações de alumínio, segundo o método proposto por BRIGGS \& KNOWLES (1).

\section{RESULTADOS E DISCUSSÃO}

O crescimento médio das raizes, em milímetros das plântulas dos cultivares, colocados durante 72 horas em solução nutritiva completa, após terem sido cultivados em solução nutritiva contendo $0,1,2,3,4$, 5,6 e $10 \mathrm{mg} /$ litro de alumínio, encontra-se no quadro 1.

QUADRO 1. Efeito comparativo de diferentes concentraçōes de alumínio na média de crescimento das raizes de quątro cultivares de trigo, em 72 horas em solução nutritiva completa, após 48 horas em solução nutritiva contendo diferentes niveis de alumínio

\begin{tabular}{ccccc}
\hline $\begin{array}{c}\text { Concentração } \\
\text { de } \\
\text { alumínio }\end{array}$ & C-3 & BH-1146 & Siete Cerros & Brevor \\
\cline { 2 - 4 } mg/litro & & & Crescimento das raizes \\
0 & 45,1 & 65,2 & 37,1 & 50,6 \\
1 & 56,7 & 68,5 & 0,0 & 0,0 \\
2 & 60,3 & 69,6 & 0,0 & 0,0 \\
3 & 47,3 & 58,1 & 0,0 & 0,0 \\
4 & 42,1 & $\mathbf{5 1 , 9}$ & 0,0 & 0,0 \\
5 & 38,0 & 47,1 & 0,0 & 0,0 \\
6 & 35,5 & 41,9 & 0,0 & 0,0 \\
10 & 21,8 & 35,7 & 0,0 & 0,0 \\
\hline
\end{tabular}


A análise da variância mostrou diferenças altament: significativas pelo teste $F$ para concentrações de alumínio, cultivares e interação concentrações de alumínio $\mathrm{x}$ cultivares.

O cultivar BH-1146, utilizado como um dos controles tolerantes ao alumínio, apresentou o maior crescimento da raiz quando não foi adicionado $\mathrm{Al}^{3+}$ na solução.

Quando foi adicionado $1 \mathrm{mg} /$ litro de $\mathrm{Al}^{3+}$ na solução, Siete Cerros e Brevor não apresentaram crescimento da raiz, sendo, pois, considerados sensíveis a esta concentração. Por outro lado, $\mathrm{BH}-1146$ e C-3 foram tolerantes a todas as concentrações de alumínio estudadas, porém em todas elas o BH-1146 foi mais tolerante em relação ao C-3.

Os resultados dos cruzamentos entre o cultivar tolerante C-3 e o sensível Siete Cerros encontram-se no quadro 2 e figuras 1,2 e 3.

QUADRO 2. Reaçōes à toxicidade, em três concentraçōes de aluminio, pelos cultivares de trigo C-3 e Siete Cerros e dos seus cruzamentos em geração $F_{1}$ e $F_{2}$, expressos em número de plantas tolerantes ao alumínio tóxico (Tol.) e de plantas sensíveis (Sens.) a esse elemento

\begin{tabular}{|c|c|c|c|c|}
\hline \multirow{2}{*}{$\begin{array}{l}\text { Cultivar ou } \\
\text { Cruzamento }\end{array}$} & \multirow[b]{2}{*}{ Tol. } & \multicolumn{3}{|c|}{ Concentração de $3 \mathrm{mg} /$ /itro de $\mathrm{Al}^{3+}$} \\
\hline & & Sens. & $\begin{array}{c}\text { Proporção esperada } \\
\text { Tol.:Sens. }\end{array}$ & $\mathrm{P}(*)$ \\
\hline & $\mathbf{n}^{\circ}$ & $\mathrm{n}^{\circ}$ & & \\
\hline C-3 & 60 & 0 & & \\
\hline Siete Cerros & 0 & 60 & & \\
\hline C-3/Siete Cerros $\left(F_{1}\right)$ & 25 & 2 & & \\
\hline C-3/Siete Cerros $\left(\mathrm{F}_{2}\right)$ & 110 & 37 & $3: 1$ & $0,90-0,9$ \\
\hline
\end{tabular}

Concentração de $6 \mathrm{mg} /$ litro de $\mathrm{Al}^{3+}$

$\begin{array}{lrrrr}\text { C-3 } & 60 & 0 & & \\ \text { Siete Cerros } & 0 & 60 & & \\ \text { C-3/Siete Cerros }\left(\mathrm{F}_{1}\right) & 20 & 12 & & <0,01 \\ \mathrm{C}-3 / \text { Siete Cerros }\left(\mathrm{F}_{2}\right) & 111 & 69 & 3: 1 & <0,01 \\ & & & 1: 3 & \end{array}$

Concentração de $10 \mathrm{mg} /$ litro de $\mathrm{Al}^{3+}$

\begin{tabular}{lrrrr} 
C-3 & 60 & 0 & \\
Siete Cerros & 0 & 60 & & \\
C-3/Siete Cerros $\left(F_{1}\right)$ & 2 & 16 & \\
C-3/Siete Cerros $\left(F_{2}\right)$ & 30 & 90 & $1: 3$ & 1,00 \\
\hline
\end{tabular}

$\left.{ }^{*}\right) \mathbf{p}=$ probabilidade de sucesso entre as freqüiências obtidas e esperadas pela hipótese de segregação de um par de genes. 


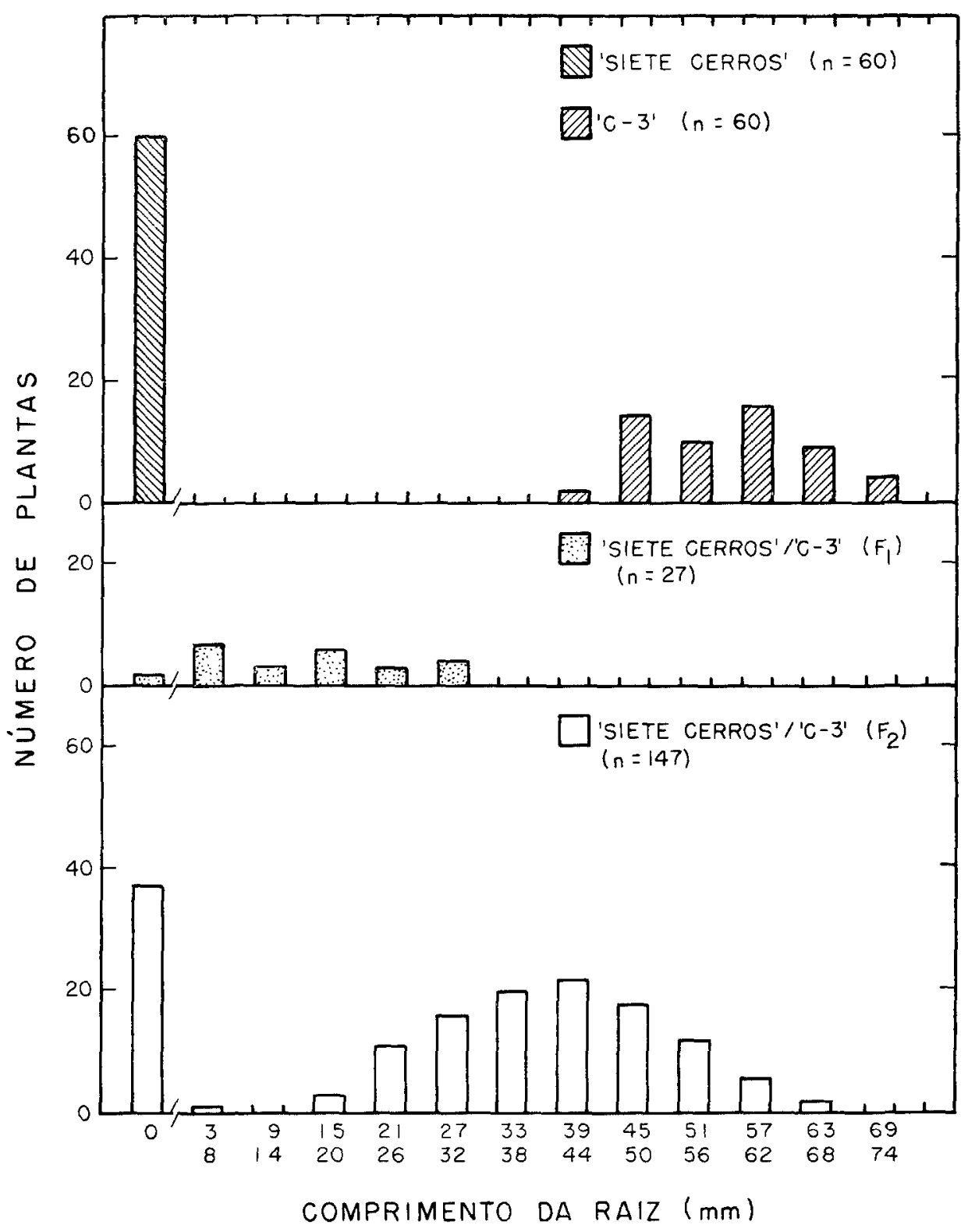

FIGURA 1. Frequiência da distribuição do crescimento das raízes dos cultivares de trigo C-3 e Siete Cerros, dos seus cruzamentos em geração $F_{1}$ e $F_{2}$, em 72 horas em solução nutritiva completa, após 48 horas em solução nutritiva contendo $3 \mathrm{mg} / \mathrm{litro}$ de $\mathrm{Al}^{3+}$. 


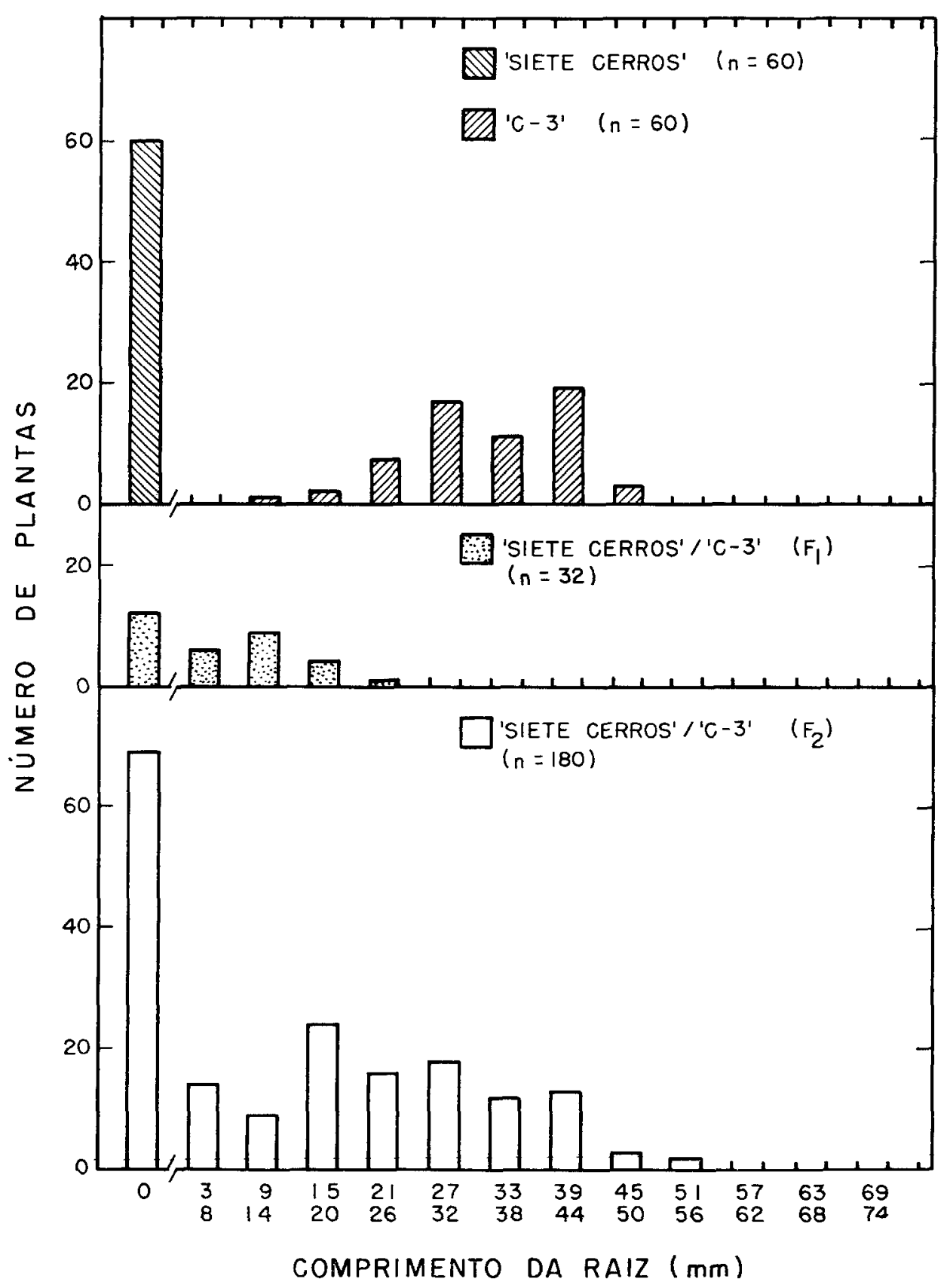

FIGURA 2. Frequiência da distribuição do crescimento das raízes dos cultivares de trigo C-3 e Siete Cerros, dos seus cruzamentos em geração $F_{1}$ e $F_{2}$, em 72 horas em solução nutritiva completa, após 48 horas em solução nutritiva contendo $6 \mathrm{mg} /$ litro de Al3\%. 


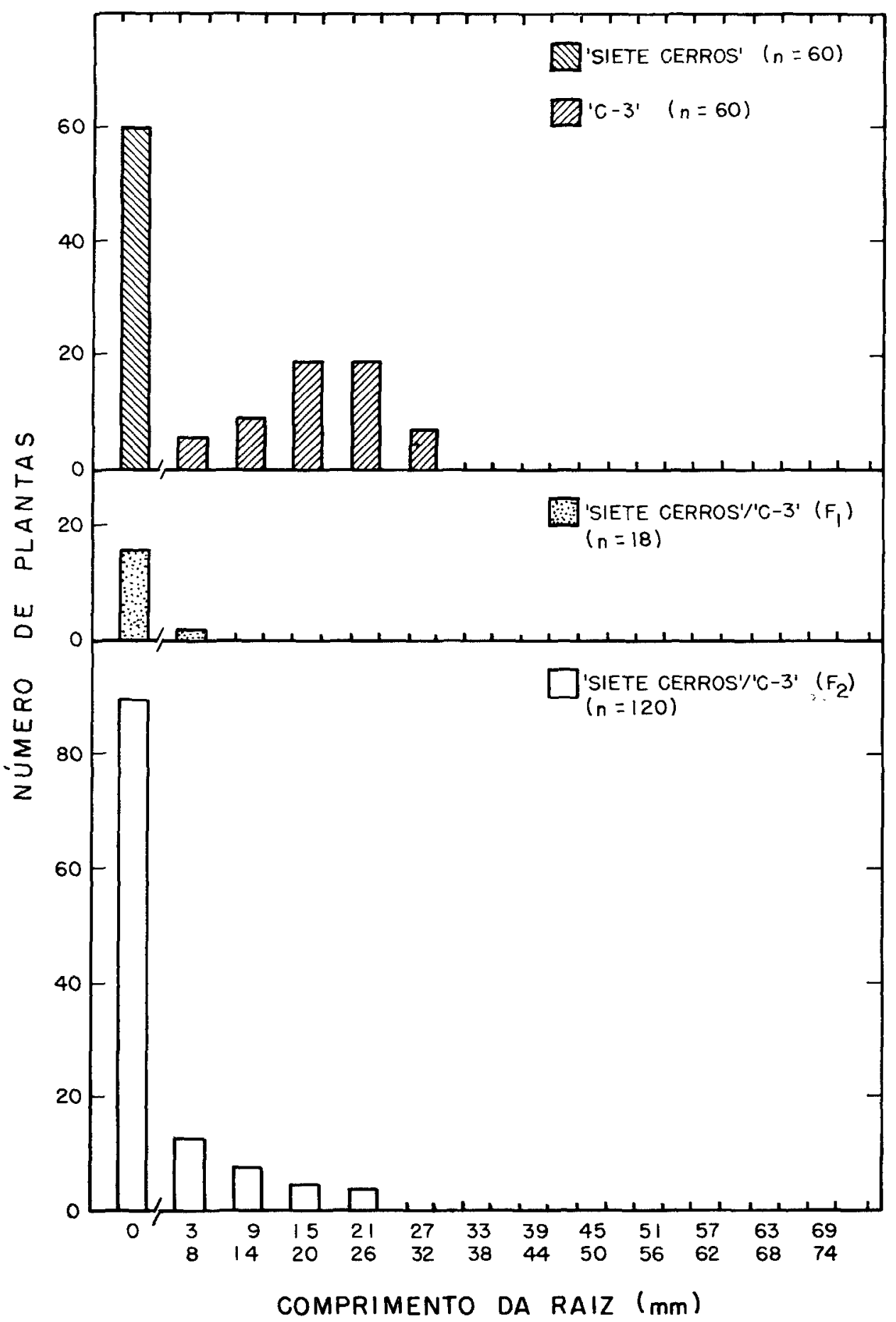

FIGURA 3. Freqüência da distribuição do crescimento das raízes dos cultivares de trigo C-3 e Siete Cerros, dos seus cruzamentos em geração $F_{1}$ e $F_{2}$, em 72 horas em solução nutritiva completa, após 48 horas em solução nutritiva contendo 10mg/litro de Al3+. 
A 3mg/litro de alumínio, a população $F_{2}$ do cruzamento estudado segregou em proporção de 110 plantas tolerantes para 37 sensíveis. Está segregação se aproximou da proporção esperada $3: 1$, com os valores de probabilidade de 0,90-0,95 de não terem ocorrido ao acaso. Tal resultado sugere que o cultivar C-3 carrega um par de genes dominantes para tolerância à toxicidade de alumínio quando se empregou a concentração de $3 \mathrm{mg} /$ litro. Comparando esses dados com os resultados da geração $F_{1}$, poder-se-ia considerar que, na concentração de $3 \mathrm{mg} /$ litro de aluminio, o cultivar C-3 teria o genótipo AA (tolerante), o Siete Cerros aa (sensivel), o $F_{1}$ seria $\mathrm{Aa}$ (tolerante) e o $\mathrm{F}_{2}$ teria a segregação 1/4 AA (tolerante), 2/4 Aa (tolerante) e $1 / 4$ aa (sensivel) ou 3/4 A- (tolerante): $1 / 4$ aa (sensivel). Esses dados estão de acordo com os citados por CAMARGO (2), concluindo que o cultivar BH-1146 diferia do Siete Cerros por um par de genes dominantes, para tolerância a $3 \mathrm{mg} /$ litro de alumínio em solução nutritiva, e com aqueles obtidos por KERRIDGE \& KRONSTAD ( $\boldsymbol{\gamma})$, onde o cultivar de trigo Druchamp diferia do Brevor, para tolerância a 1,6mg/litro de aluminio, por um par de genes dominantes.

Quando as plantas em geração $F_{1}$ foram testadas a $6 \mathrm{ng} /$ litro, observou-se a proporção de 20 plantas tolerantes para 12 sensíveis, isto é, a proporção de 1,6:1. Como foi considerado que as plantas $F_{1}$ teriam o genótipo $\mathrm{Aa}$, nessa concentração o genótipo heterozigoto não condicionou total tolerância ao alumínio. Observando-se também as plantas $F_{2}$, cultivadas com $6 \mathrm{mg} /$ litro de $\mathrm{Al}^{3+}$ na solução, observaram-se 111 plantas tolerantes para 69 sensíveis, num total de 180 plantas testadas. Com base nos resultados anteriores (3mg/litro), eram esperadas 45 plantas com o genótipo AA (tolerantes), 90 plantas Aa (tolerantes) e 45 aa (sensíveis). Se considerarmos que 90 plantas da geração $F_{2}$ teriam o mesmo genótipo (Aa) das plantas em geração $F_{1}$, e que neste sc encontrou a proporção 1,6:1 de plantas tolerantes para sensíveis, empregando-se esta proporção para as 90 plantas $(\mathrm{Aa})$ da geração $\mathrm{F}_{2}$ seriam esperadas 56 plantas tolerantes para 34 sensíveis. Somando-se estas 56 plantas tolerantes (Aa) com as 45 plantas tolerantes (AA) esperadas, obter-se-iam 101 plantas tolerantes para 79 plantas sensiveis, o que está bem próximo da proporção obtida 111:69. Logo, se a população $F_{2}$ estudada fosse somente testada na concentração de $6 \mathrm{mg} /$ litro de $\mathrm{Al}^{3+}$, poder-se-iá concordar com os resultados obtidos por LAFEVER \& CAMPBELL (8), que, testando a $8 \mathrm{mg}$ /litro de $\mathrm{Al}^{3+}$ uma população $\mathrm{F}_{2}$ originária do cruzamento de um cultivar tolerante e outro sensivel, concluíram que a seleçäo de plantas sensíveis na geração $F_{2}$ seria efetiva, porém a seleção de plantas tolerantes ou de tolerância intermediária seria menos eficiente, indicando que a herança era mais complexa do que um único par de genes.

Quando as plantas $F_{1}$ foram testadas em solução nutritiva contendo $10 \mathrm{mg} /$ litro de alumínio, praticamente todas foram sensiveis a essa concentração (quadro 2 e figura 3). Logo, o genótipo Aa mostrou-se sensivel a $10 \mathrm{mg} /$ litro de aluminio. Pelo comportamento da população $\mathbf{F}_{2}$ 
nessa concentração, verificou-se a segregação de 30 plantas tolerantes para 90 sensíveis. Considerando os dados obtidos pela população $F_{1}$, esperava-se na população $F_{2}$ a seguinte proporção: 30 plantas com genótipo AA (tolerantes), 60 plantas com genótipo Aa (sensiveis) e 30 plantas aa (sensiveis). Logo, os dados obtidos concordam com a proporção esperada de uma planta tolerante para três sensíveis com alta probabilidade de não serem ao acaso, pelo teste de quiquadrado, à concentração de $10 \mathrm{mg} /$ litro de $\mathrm{Al}^{3+}$. Por outro lado, se a população fosse somente estudada a $10 \mathrm{mg}$ /litro de aluminio, poder-se-ia considerar que a sensibilidade fosse devida a um par de genes dominantes ou que a tolerância fosse devida a um par de genes recessivos. Tais resultados, obtidos com a concentração de $10 \mathrm{mg} /$ litro de $\mathrm{Al}^{3<}$, concordam com os relatados por CAMARGO (2).

No quadro 3 são apresentados os valores da herdabilidade em sentido amplo dos crescimentos das raízes dos genótipos de trigo cultivados em soluções nutritivas completas com tratamentos prévios de 48 horas em solução contendo 3 , 6 e $10 \mathrm{mg} /$ litro de alumínio.

QUADRO 3. Herdabilidade em sentido amplo para comprimento rédio das raízes primárias centrais de trigo cultivadas por 72 horas em soluções nutritivas completas com tratamentos prévios de 48 horas em soluções contendo 3,6 e 10mg/litro de alumínio

$\mathrm{mg} /$ litro

$\begin{array}{rrr}3 & 0,849 & 0,678 \\ 6 & 0,860 & 0,794 \\ 10 & 0,725 & 0,895\end{array}$

(a) $\mathrm{H}=\left\{\operatorname{Var} \mathrm{F}_{2}-\left(\operatorname{Var} \mathrm{P}_{1}+\operatorname{Var} \mathrm{P}_{2}+\operatorname{Var} \mathrm{F}_{1}\right) / 3\right\} / \operatorname{Var} \mathrm{F}_{2}$

(b) $\mathrm{H}=\left(\operatorname{Var} \mathrm{F}_{2}-\operatorname{Var} \mathrm{F}_{1}\right) / \operatorname{Var} \mathrm{F}_{2}$

Verificaram-se valores altos da herdabilidade em sentido amplo ao considerar o crescimento das raizes em diferentes concentrações de alumínio em soluções nutritivas. Com tais valores, e em conformidade com os resultados já apresentados e discutidos, era de esperar que fosse possivel transferir a tolerância ao alumínio do cultivar C-3 para o Siete Cerros.

\section{CONCLUSÕES}

1. Os cultivares $\mathrm{BH}-1146$ e $\mathrm{C}-3$ foram tolerantes a $10 \mathrm{mg} /$ litro de alumínio em solução nutritiva, ao passo que Siete Cerros e Brevor foram 
sensiveis a $1 \mathrm{mg} /$ litro. $\mathrm{BH}-1146$ foi mais tolerante que $\mathrm{C}-3 \mathrm{em}$ todas as concentraçóes de alumínio estudadas.

2. O cultivar C-3 diferiu do Siete Cerros por um par de genes dominantes para tolerância, quando estudados em solução nutritiva contendo $3 \mathrm{mg}$ /litro de alumínio. Houve uma quebra gradual da dominânciáa do par de genes responsável pela reação de tolerância quando se empregou a concentração de $6 \mathrm{mg}$ /litro na solução, sugerindo também que genes adicionais poderiam estar envolvidos na determinação do nivel de tolerância. O cultivar Siete Cerros diferiu do C-3 por um par de genes dominantes para sensibilidade, quando estudados em solução nutritiva contendo $10 \mathrm{mg}$ /litro de $\mathrm{Al}^{3+}$, ou o C-3 diferiu do Siete Cerros por um par de genes dominantes para tolerância, nessa concentração, se for considerado que as plantas heterozigotas das gerações $F_{2}$ e $F_{1}$ foram sensíveis.

3. Altos valores de herdabilidade em sentido ampio indicaram que a seleção para tolerância ao aluminio seria efetiva na população proveniente do cruzamento entre um cultivar tolerante (C-3) e um sensivel (Siete Cerros).

4. Havendo grandes populações $F_{2}$, seria mais interessante selecionar em altas concentrações de aluminio (10mg/litro) ria solução, pois seriam eliminadas as plantas sensiveis (homozigotas recessivas e heterozigotas) e selecionadas as tolerantes homozigotas. Por outro lado, seria de interesse utilizar baixas concentrações de alumírio (3mg/litro) na solução quando pequenas populações $F_{2}$ fossem disponiveis, pois seriam eliminadas somente as plantas sensiveis (homozigotas recessivas) e selecionadas as tolerantes (homozigotas e heterozigotas) e na geração seguinte, com maior disponibilidade de sementes, poderiam ser testadas a $10 \mathrm{mg} /$ litro para se ter maior progresso no trabalho de melhoramento genético.

\section{SUMMARY}

\section{WHEAT BREEDING:}

\section{INHERITANCE OF TOLERANCE TO THREE DIFFERENT ALUMINUM CONCENTRATIONS IN NUTRIENT SOLUTION}

Four wheat cultivars: $\mathrm{BH}-1146, \mathrm{C}-3$, Siete Cerros and Brevor were tested in nutrient solution with $0,1,2,3,4,5,6$ and $10 \mathrm{mg} / 1$ of $\mathrm{Al}^{3+}$. It was demonstrated that B-1146 and C-3 presented tolerance to $10 \mathrm{mg} / \mathrm{l}$ of $\mathrm{Al}{ }^{3+}$ whereas Brevor and Siete Cerros were sensitive to $1 \mathrm{mg} / 1$ of $\mathrm{Al}^{3+}$. It was considered tolerant the plant that was able to show root regrowth of the central primary root in the complete nutrient solution after a treatment in a solution containing a particular amount of aluminum. Seeds of $\mathrm{C}-3$ and Siete Cerros, considered parental lines, and the $F_{1}$ and $\mathbf{F}_{2}$ populations from the crosses between them, were tested in nutrient solutions where 3,6 and $10 \mathrm{mg} / \mathrm{l}$ of aluminum were applied. The results showed that C-3 differed from siete Cerros by one pair of dominant genes for tolerance at $3 \mathrm{mg} / \mathrm{l}$ of aluminum. There was a gradual decrease of dominance of the gene pair responsable for the tolerance reaction when it was used $6 \mathrm{mg} / 1$ of aluminum in 
the solution. The cultivar Siete Cerros differed from C-3 by one pair of dominant genes for susceptibility at $10 \mathrm{mg} / 1$ of aluminum or C-3 differed from Siete Cerros by one dominant gene even at $10 \mathrm{mg} / 1$ of $A{ }^{3+}$ if it was considered that the heterozygous individuals from the $F_{1}$ and $F_{2}$ populations showed reaction of susceptibility. Heterozygous seedlings of $F_{1}$ and $F_{2}$ populations from the cross $\mathrm{C}-3 /$ Siete Cerros, considered tolerant at $3 \mathrm{mg} / \mathrm{l}$ of $\mathrm{Al} 3+$, showed a decrease in tolerance at $6 \mathrm{mg} / 1$ and susceptibility at $10 \mathrm{mg} / 1$. High broad sense heritability estimates $(0.725$ to 0.895$)$ for aluminum tolerance to three different levels were obtained suggesting that selection for tolerance would be effective in the $F_{2}$ population from the studied cross. It would be interesting to select for aluminum tolerance using solutions containing $10 \mathrm{mg} / \mathrm{l}$ of $\mathrm{Al}^{3+}$ when large $\mathrm{F}_{2}$ populations are provided being possible to eliminate the sensitive plants (recessive homozygous and heterozygous) and select the homozygous tolerant plants. On the other hand, when small $\mathrm{F}_{2}$ populations are available it would be desirable to select for tolerance using solutions with $3 \mathrm{mg} / 1$ of $\mathrm{Al}$ is when only the sensitive plants (recessive homozygous) would be discarted and the tolerant plants (homozygous and heterozygous) would be used in the breeding program.

\section{REFERENCIAS BIBLIOGRĀFICAS}

1. BRIGGS, F.N. \& KNOWLES, P.F. Introduction to plant breeding. Davis, Reinhold Publishing Corporation, 1977. $426 \mathrm{p}$.

2. CAMARGO, C.E.O. Melhoramento do trigo. I. Hereditariedade da tolerância ao alumínio tóxico. Bragantia, Campinas, 40:33-45, 1981.

3. —_ KRONSTAD, W.E.; METZGER, R. Parent-progeny regression estimates and associations of height levels with aluminum toxicity and grain yield in wheat. Crop Science, 20:355-358, 1980.

4. —— \& OLIVEIRA, O.F. Tolerância de cultivares de trigo a diferentes níveis de alumínio em solução nutritiva e no solo. Bragantia, Campinas, 40:21-31, 1981 .

5. CAMPBELL, L.G. \& LAFEVER, H.N. Heritability and gene effects for aluminum tolerance in wheat. In: INTERNATIONAL WHEAT GENETICS SYMPOSIUM, 5., New Delhi, India, 1978. Proceedings. p. 963-967.

6. FOY, C.D. Differential aluminum and manganese tolerance of rlant species and varieties in acid soils. Ciência e Cultura, São Paulo, 28:150-155, 1976.

7. KERRIDGE, P.C. \& KRONSTAD, W.E. Evidence of genetic resistance to aluminum toxicity in wheat. Agronomy Journal, 60:710-711, 1968.

8. LAFEVER, H.N. \& CAMPBELI, L.G. Inheritance of aluminum tolerance in wheat. Canadian Journal of Genetics and Cytology, 20:355-364, 1978.

9. MOORE, D.P.; KRONSTAD, W.E.; METZGER, R. Screening wheat for aluminum tolerance. In: WRIGHT, Madison J., ed. Workshop on Plant Adaptation to Mineral Stress in Problem Soils, Beltsville, Maryland, 1976. Proceedings. Ithaca, Cornell University, 1976. p.287-295. 